\title{
Supporting the Dissertation Process with Grad Tools
}

\author{
Michelle Bejian Lotia, Stephanie D. Teasley \\ Usability, Support and Evaluation Lab, University of Michigan \\ 3350 Duderstadt Center \\ 2281 Bonisteel Blvd. \\ Ann Arbor, MI 48109-2094 \\ 1-734-615-4333 \\ [beejoo, steasley]@umich.edu
}

\begin{abstract}
Heavy use of an online collaboration and learning environment (CLE) at a large research university led the graduate school to consider how a CLE might support dissertation committees. The project team conducted focus groups with 38 student, faculty, and administrative staff to determine system requirements. Results showed that users would benefit from a tool designed to facilitate the dissertation process, especially if social norms and workbenefit disparity issues were directly addressed. The development team designed and built a "dissertation navigator" in our CLE. 645 users have adopted Grad Tools, suggesting that some traditional groupware design challenges have been overcome.
\end{abstract}

\section{Categories and Subject Descriptors}

H.5.3 [Group and Organization Interfaces]: Computersupported cooperative work

\section{General Terms}

Design, Human Factors

\section{Keywords}

Collaboration, Higher Education, Online Learning Environments

\section{INTRODUCTION}

Research on the practice of science has clearly demonstrated the social nature of knowledge construction [1,2,3]. While this work has carefully documented social practices in laboratories, the focus is typically on the lead scientist with some description of the role of graduate students (and others) in the production of the work of the lab. The path to Ph.D. has not been fully characterized in this line of work, especially the activities outside that lab that are necessary to complete the degree. During the pursuit of a doctoral degree, graduate students work with various committees to demonstrate intellectual mastery, design an original research plan, conduct the research, report their results, defend their findings and produce a dissertation, the final academic requirement. While students specifically interact with committee members, there are other university personnel involved in the

Permission to make digital or hard copies of all or part of this work for personal or classroom use is granted without fee provided that copies are not made or distributed for profit or commercial advantage and that copies bear this notice and the full citation on the first page. To copy otherwise, or republish, to post on servers or to redistribute to lists, requires prior specific permission and/or a fee.

GROUP'05, November 6-9, 2005, Sanibel Island, Florida, USA.

Copyright 2005 ACM 1-59593-223-2/05/0011...\$5.00. process, such as doctoral program chairs, research administrators, and departmental and graduate school administrative assistants.

The doctoral degree process takes several years and while there are standard official milestones, university departments typically define their own specific requirements. Coordinating and communicating these requirements is challenging even for department staff. For example, advancing to candidacy is an official milestone that indicates the student is prepared to begin their dissertation research. However, the requirements to advance to candidacy - courses, preliminary exams, internships - can vary between departments and requires a high degree of consensus about when requirements have been met. Typically department staff monitors student progress, consult with faculty advisors and report satisfactory progress on each milestone to the graduate school. The graduate school stewards that data and is the official entity that ultimately confers the doctoral degree.

Supporting coordination during the doctoral degree process is critical to ensure that students do high-quality research and complete their degrees. The graduate school was already pursuing several strategies for lowering attrition and shortening time-todegree, including providing many informational resources and workshops for students and faculty. In addition to managing the administrative aspects of the degree process, the graduate school's own research with their students found that that many students also wanted intellectual and career support - "someone who is concerned about them and how they fit into their wider discipline" [4]. Since coursework and research collaborations among faculty were already making use of the campus CLE, the graduate school decided to investigate opportunities to support mentoring and committee work using the CLE. The project team decided it was important to research the dissertation process, actors, and social environment from a groupware design perspective so that any newly developed tools would meet the right needs with a lowcost, high-benefit design.

Groupware is notoriously difficult to design so that it is successfully adopted [5,6]. Particular challenges include software whose use disrupts organizational norms or requires more work from the actors who benefit less from it. In order to understand the groupware design challenges in supporting the doctoral degree process and how to overcome them in the design of a new groupware tool, we chose to do qualitative research on the existing Ph.D. process at our academic institution, which is a large research university in the Midwest. We structured our investigation to better understand the nature of the work and the relevant roles played by students, faculty and staff, and to identify problems that might be solved with the use of a groupware tool. 


\section{RESEARCH METHOD}

We were agnostic about potential design solutions in conducting our needs analysis. First, we conducted a brainstorming exercise with faculty and students on the graduate school's executive board $(n=16)$. We asked them to note three of the best aspects of serving on a dissertation committee, three of the worst aspects of serving on a dissertation committee, and ways they thought technology could support committee work. Participants answered the three questions on individual note cards, and we facilitated a brief discussion of their comments.

Comments from the brainstorming session helped us frame our next exercise, conducting 8 focus groups and interviews with a total of 38 students, faculty, department staff, and graduate school staff. In the focus groups we investigated three issues: 1) the administrative process of completing appropriate requirements, 2) the research process, including communication and workflow between students and faculty, and 3) the work process and the communication and collaboration tools currently used to do it. The perspectives voiced in the focus groups suggested several software requirements, one of which was submission of an electronic thesis or dissertation (ETD). To validate and prioritize requirements, we conducted a follow-up questionnaire online and on paper and asked participants to rate the importance of each requirement to their work. We received a $76 \%$ response rate, with 29 of 38 questionnaires returned.

\section{FINDINGS}

\subsection{Administrative Process}

The administrative steps in the Ph.D. degree process were unclear to many of our participants, especially since departments and the graduate school specify the requirements for different parts of the process. Faculty and staff were concerned that students may not have clear guidance, but were unsure themselves of many of the administrative specifics. For faculty and students, the department administrative staff are the reference point and organizational memory for how process takes place. These staff explain to faculty what administrative work needs to be done for a particular student at his or her point in the process. The staff also monitor student progress throughout to head off problems that may cause a student to miss an important deadline, graduate later than planned, or even drop out of the program. The administrative staff have various methods to keep track of student progress, such as paper files and databases, which seem to be determined by the number of students in the department and the individual staff member's comfort with technology.

At the graduate school, the administrative staff are responsible for approving passage of the official milestones when they receive paper forms from the departments via campus mail and fax. The graduate school has two database systems that administrative staff use every day to track this information. They meet with students only very late in the Ph.D. process to prepare the students for the logistical steps necessary to complete the oral defense and the preparation of the official version of the final dissertation document. Graduate school staff acknowledged that it is difficult for students to understand the administrative details while trying to focus on their research. While there were many informative resources available to help alleviate confusion, these were considered underutilized.

\subsection{Research Process}

During the final research phase of graduate work, there are few administrative requirements so students are generally in less contact with their departments. Leaving a doctoral program at this point is so common [7] that the academic community uses the term "ABD" (All But Dissertation) to identify those who completed all of the doctoral requirements except the dissertation itself. Many students and faculty are aware of this and thought that students working individually on their research (not as a member of a lab group) or off-campus were more at risk of becoming isolated and drifting, and these students could benefit from different ways to stay in touch with their committee.

There was consensus among all the subjects that the Ph.D. research process is and should stay the responsibility of the student. However, the relationship between the student and his or her committee chair often determines the extent to which the entire committee participates in advising the student early in the process. We found that departments have different norms for when the committee is formed, how and where the work should take place, and how often and with whom the student should communicate. The diversity of social norms that surround the research process suggested that online collaboration features in a dissertation support tool, while useful for some committees, might be used differently or not at all by others.

\subsection{Current Work Tools}

Students reported that they felt they already had the basic tools to communicate and collaborate. In particular, all student participants used email, face-to-face formal or informal meetings, paper, and phone. Some also reported using email attachments and email groups to communicate with their chair or committee.

The perceived usefulness of these technologies varied, however. Emailing a draft was useful, but faculty usually sent comments back directly to the student and did not share them with the whole committee. Many students and some faculty wanted comments to be shared more widely, but there was some tension about the benefits of having an open collaborative environment for dissertation work. Several faculty reported that intellectual interaction with their colleagues was one of the best aspects of serving on a dissertation committee. Interacting online, however, was not universally appealing. One faculty member said "I fear that like [the CLE], this will make life much better for the student and much more time-consuming and effortful for the faculty." Most students said that any dissertation support tool would be welcome, but only if it did something another tool wasn't already doing and wasn't just "one more place to go."

\section{DESIGN}

Our findings indicated opportunity to support dissertation work with a careful design goal - to benefit students without requiring a disruptive shift to social norms or requiring more work from other actors. The dissertation process, we found, has different characteristics at different points that would need different types of support. Individual and informal parts of the work would need flexibility to be shaped around social norms. The standard and formal parts of the work, like completing requirements, would require consistency and accuracy. 
The tools available in our existing CLE were designed to be flexible enough to accommodate various instructional styles, so it could help support the individual and informal parts of the work. But there was no tool to help support the standard and formal parts of the dissertation process. We decided that an important feature of a dissertation support tool would be a "dissertation navigator" that shows the steps an individual student must follow and their progress. In our follow-up questionnaire, our participants agreed that this would be the most critical feature. We designed and developed the Dissertation Checklist as a unique new tool that is presented with the other tools available in our local CLE. This combination of tools appears as a specialized site called "Grad Tools."

The Dissertation Checklist tool within Grad Tools has three levels - the graduate school, the department, and the student/committee. At the graduate school level, it presents an overall view of the official milestones, requirements, and recommendations in a simple single-page list. For each step, icons indicate who is responsible for completing a step or verifying that it has been completed. We built a one-way data integration tool that allows graduate school staff to update student progress without having to enter data in another tool, or deal with security concerns that would come with allowing changes to official data through the Grad Tools interface. Since the graduate school was already responsible for tracking the official milestones that lead to degree conferral, they did not need to collect additional data from the checklist. We also included a feature to add hyperlinks within steps, so that staff could refer students and faculty to forms or other informational resources online.

At the department level, the Dissertation Checklist inherits the steps from the graduate school, and administrative staff can add department requirements. Department staff manage their checklists in their own administrative Grad Tools site, in which they can also track the progress of all of their students. When department staff add a new step to their master departmental checklist, it is added to the checklists of all of their students. Department-specific steps are used to indicate who is responsible for particular administrative details, when that work should be done, and what requirements need to be fulfilled to reach official milestones. Administrative staff can also add hyperlinks to departmental resources available online.

At the student level, the Dissertation Checklist contains steps from department checklist, so students get a personalized view of the process they need to complete. Progress on the official milestones, like passing preliminary exams, forming the dissertation committee, or advancing to candidacy, is checked off by the graduate school data update. In addition, students and their committee members can expand the checklist into a work plan by adding steps that communicate the students' intentions and reflect consensus about goals and deliverables.

Currently, the use of Grad Tools is not required by the graduate school or any department, and is completely driven by the student. If they want to use Grad Tools, students create their own Grad Tools site and are automatically linked to the appropriate department. By default, only the student has access to his or her Grad Tools site. When and if they have a committee that wants to participate, the student grants access to the individual members of the committee. If committee members change, students can easily alter the membership of the site. Graduate school and department staff can always see a student's checklist, so that they can confirm and track student progress. Even if a student's committee members do not want to collaborate online, the student still benefits from having the Dissertation Checklist to clarify his or her requirements.

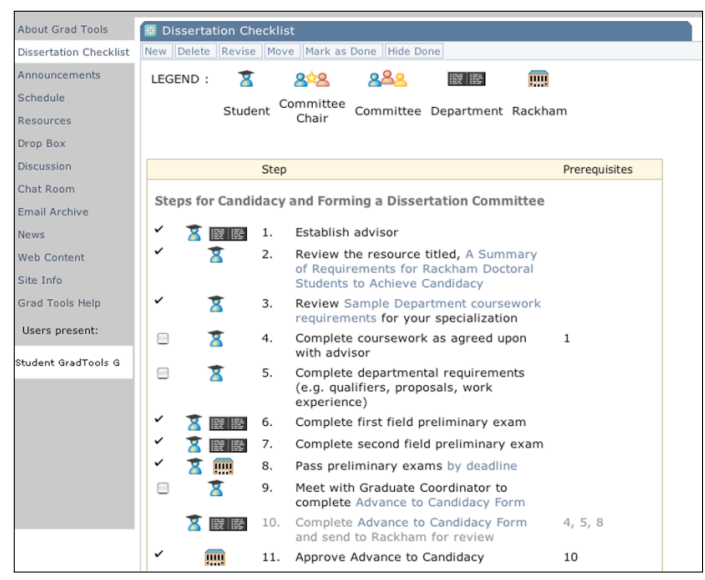

Figure 1: Dissertation Checklist within Grad Tools.

The Dissertation Checklist supports the formal aspects of the dissertation process; the informal aspects are supported by other features in Grad Tools that come from integration with our CLE. These include file storage, threaded discussion, an email group, and email notification of activity. Additionally, integration with our CLE means Grad Tools is accessible in same environment as course websites or collaboration websites, so it is always accessible in the course of normal daily work for both students and faculty. The CLE that incorporates Grad Tools is currently used by over $70 \%$ of students and faculty on our campus.

\section{USE}

We deployed Grad Tools first to departments by creating 91 department Grad Tools sites, and assisting department staff with customizing their Dissertation Checklists. On December 1, 2004, Grad Tools became publicly available to students. We publicized Grad Tools' availability on the graduate school's web site and the home page of the campus CLE. We also sent information about Grad Tools to the graduate student email list. At the present time, 645 doctoral students from 80 schools and departments are using Grad Tools. Of these students, over half $(56.2 \%)$ have reached candidacy. Of all student users, $10.8 \%$ are in departments where administrative staff have customized the checklists with department requirements.

We have seen exciting uses of Grad Tools that suggest that it benefits students with minimal disruption to social norms. The first student to graduate who had used Grad Tools said:

"This list, in particular, has been VERY useful to me. I especially like the links in many of the checklist items. I was able to quickly get the info I needed. There is so much administrative stuff that has to happen in the last 3-4 weeks, and it would have been much more overwhelming without Grad Tools. I wish it had been available earlier in my graduate career because I think it has a lot of powerful capabilities for grad students just starting out."

Department staff have embraced Grad Tools as well, not only to keep track of student progress, but as a way to share process 
information and other resources with their students. For example, a staff member in the music program has added steps to describe the administrative process students should complete, and also posted links to job openings, department forms, and department deadlines.

A junior faculty member in the same department, who has many advisees on-campus and off, has promoted the use of Grad Tools to his students.

"I've been having each of my students set up a Grad Tools site. This helps them to keep track of their progress and to keep an archive of their work as they progress through the program. I've also set up an Advisees project site in [the CLE] to which I have each of the students link their schedules. This way I can see everyone's deadlines at a glance. Finally, I created an Advisees blog in SiteMaker and I have this linked to the Advisees site. This allows me to bring up issues for general discussion - such as recent trips to professional conferences and to help stay in touch with students who are temporarily off campus."

The experiences above show that Grad Tools can provide benefits through increasing access to information and social support systems to actors other than students, should they decide to adopt the technology.

\section{LESSONS LEARNED}

The needs analysis quickly showed that students needed coordination support whether or not they used online collaboration tools. Focusing only on collaboration tools or a tool for ETD would not have revealed a significant need to support the flow of the doctoral degree process. Grad Tools attracts students with its process coordination support, and once they begin to use it, provides opportunities to begin or continue their committee work online.

As a workflow tool, the Dissertation Checklist has obvious applications for different research methods and models, as well as other ordered and multi-player processes in academic environments (e.g., admissions applications, degree audits, and much of the functionality discussed in the context of electronic portfolio design). Academics is not the only context in which this combination of workflow and collaboration tools would be useful. Grad Tools provides a general design framework for online group work that can be tailored to fit specific tasks, organizational contexts, and group and individual goals.

\section{FUTURE WORK}

Future research on Grad Tools will focus on questions about the adoption and use of this environment by Ph.D. students and their committees. Reports from the early adopters have stressed the value of the Dissertation Checklist to help shepherd students through the administrative steps to degree. All the actors involved in the process - students, faculty, and administrators at the department and graduate school - desired this functionality and its use appears to integrate well within existing social norms or practices. Even users whose checklist reflected only the graduate school's requirements reported the value of this tool, and our data show that the addition of department-specific items is not driving use. As the overall adoption of Grad Tools increases, it will be interesting to track when departments decide to develop their own customized checklist and add their required milestones. User surveys and an evaluation of time-to-degree and attrition for Grad Tools users versus non-Grad Tools users will demonstrate how students benefit from this tool.

Given the variability in norms about the nature and frequency of collaboration between graduate students and their committees, it remains to be seen who uses the functionality beyond the checklist, how they do so, and when. Mixed opinions about the desirability of a tool that increases the expectation of more communication between students and their committee suggests that the use of Grad Tools for this purpose will be highly individualized. Yet we do have data showing that users are adopting the tool very early in their graduate careers (well before they begin the dissertation), and utilizing announcements and file sharing to pass along information to committee members. It may be that a clear mechanism for increasing the communication in one direction, from student to faculty, will be considered a win by both parties. When and if the tool also is used to increase communication in the other direction, from faculty to students, remains to be seen. Given the diversity of our academic institution and trajectory of local adoption, we believe that data from future assessments and development of Grad Tools will generalize for supporting students pursuing doctoral study at many other institutions.

\section{ACKNOWLEDGMENTS}

We thank the many students, faculty and staff who participated in this project, especially Dick Ellis, Rex Patterson, Louis King, and Melissa Mazmanian. Support was provided by the Collaboratory for Advanced Research and Academic Technologies and the Horace H. Rackham School of Graduate Studies.

\section{REFERENCES}

[1] Mukerji, C. (1996). The collective construction of scientific genius. In Y. Engestrom \& D. Middleton (Eds.), Cognition and communication at work (pp. 257-278). Cambridge, England: Cambridge University Press.

[2] Knorr-Cetina, K. (1981). The manufacture of knowledge. New York: Pergamon.

[3] Latour, B. \& Woolgar, S. (1979). Laboratory life. Beverly Hills, California: Sage.

[4] Rackham School of Graduate Studies. (2004). How to get the mentoring you want: A guide for graduate students at a diverse university. Retrieved May 16, 2005 from Horace H. Rackham School of Graduate Studies Web site: http://www.rackham.umich.edu/StudentInfo/Publications

[5] Grudin, J. Groupware and social dynamics: eight challenges for developers. Communications of the ACM, 37, 1 (Jan. 1994), 92-105.

[6] Orlikowski, W. Learning from Notes: organizational issues in groupware implementation. In Proceedings of the ACM conference on Computer-supported cooperative work (CSCW '92). (Toronto, Ontario, Canada, November $1-4$, 1992). ACM Press, New York, NY 1992, 362-369.

[7] Bowen W. G, \& Rudenstine, N. L. (1992). In Pursuit of the $P h D$. Princeton, NJ: Princeton University Press. 